\title{
DARI MIANZI DAN LIAN MENUJU FACE: \\ DARI KEARIFAN LOKAL CINA MENUJU TEORI KESANTUNAN YANG MENDUNIA
}

\author{
Agung Pramujiono \\ Jurusan Pendidikan Bahasa dan Sastra Indonesia, FKIP, Universitas PGRI Adi Buana \\ Jl. Ngagel Dadi III-B/37, Surabaya 60245, Indonesia \\ pram4014@yahoo.com
}

\begin{abstract}
The politeness theory of Brown and Levinson (1987) about face is regarded as one very influential. In fact, it was rooted from Eastern local wisdom (ancient China), that is "mianzi" and "lian". Mianzi represents social perceptions of one's self-esteem built through lian as one's morality. Politeness and limao have the same pragmatic basis but they can be perceived differently due to the varied cultural contexts underlying a speech community. In the intercultural pragmatics study, the differences should not form the sources of conflict but they should even be considered as varieties of pluralities about which the interactants should be understood in order that interpersonal communication activities can run harmoniously and can be avoided from all kinds of conflict and friction.
\end{abstract}

Keywords: politeness theory, face, Brown and Levinson theory, Mianzi and Lian, intercultural pragmatics

\begin{abstract}
ABSTRAK
Teori kesantunan Brown dan Levinson (1987) tentang wajah dianggap sebagai salah satu yang sangat berpengaruh. Namun kenyataannya, teori tersebut berakar dari kearifan lokal Timur (Cina kuno), yaitu "mianzi" dan "lian". Mianzi merupakan persepsi sosial seseorang diri yang dibangun melalui lian sebagai moralitas seseorang. Kesopanan dan limao memiliki dasar pragmatis yang sama tetapi dapat dirasakan berbeda karena konteks budaya yang bervariasi yang mendasari budaya bertutur suatu masyarakat. Dalam studi antarbudaya pragmatik, perbedaan seharusnya tidak membentuk akar-akar konflik tetapi seharusnya dianggap sebagai varietas kemajemukan tentang interaksi yang harus dipahami agar kegiatan komunikasi interpersonal dapat berjalan harmonis dan dapat terhindar dari segala macam konflik dan gesekan.
\end{abstract}

Kata kunci: teori kesantunan, wajah, teori Brown dan Levinson, Mianzi dan Lian, pragmatik antarbudaya 


\section{PENDAHULUAN}

Kajian tentang kesantunan (politeness) selalu merujuk pada teori yang dikembangkan oleh pakar dari barat. Beberapa contoh pakar di antaranya Lakoff (1973) yang dianggap sebagai Bapak Teori Kesantunan, Leech (1993) dengan maksim-maksim kesantunannya, dan Brown- Levinson (1987) dengan teori FTA (face threatening acts). Telaah tentang kesantunan kemudian berkembang pada kajian-kajian ketidaksantunan (impoliteness) yang dimotori oleh Cullpeper dan Boushfield (2008) dengan asumsi bahwa tidak elok mengkaji kesantunan tanpa melihat sisi yang lain, yaitu ketidaksantunan.

Akar teori kesantunan tersebut sebenarnya berasal dari nilai kearifan lokal yang berasal dari Cina, yaitu mianzi dan lian yang digali oleh Hsien Chin Hu dari falsafah K’ung Fu Tzu (orang Indonesia menyebutkan Konghucu) yang kemudian dielaborasi oleh Goffman $(1959,1967)$ menjadi konsep face (muka) dalam teori dramaturgi. Pembicaraan kemudian berkembang dengan upaya pendikotomian konsep muka menjadi dua, versi Timur dan versi Barat. Semula muka didefinisikan sebagai atribut pribadi yang ada dan ditemukan pada semua masyarakat dan ia bersifat universal. Setiap orang dinisbatkan untuk memikul tanggung jawab dalam upaya memuliakan wajahnya sendiri dan wajah anggota masyarakat lainnya (Aziz, 2007). Kemudian konsep tersebut dibedakan bahwa konsep muka antara barat dan timur itu berbeda. Konsep muka versi timur dianggap lebih bersifat sosial, sedangkan barat lebih bersifat individual, egalitarian, lebih menekankan pada pertimbangan kebebasan individu (Leech, 2007). Polemik Timur-Barat ini kemudian menggelitik Leech untuk menulis artikel "Politeness: is there an East-West divide?" yang dimuat dalam Journal of Politeness Research Language, Behavior, Culture edisi Juli 2007.

Dalam makalah ini, penulis ingin menelaah bahwa teori-teori kesantunan yang mendunia yang dikemukakan oleh pakar Barat sebenarnya berangkat dari nilai kearifan lokal Timur (Cina). Masalah yang akan dipaparkan lebih lanjut dalam makalah ini yaitu: (1) kearifan lokal Cina: mianzi dan lian, (2) konsep face dan teori kesantunan Brown dan Levinson, (3) model kesantunan timur Yueguo Gu, (4) teori kesantunan: perlukah pemisahan antara Timur dan Barat?

\section{PEMBAHASAN}

\section{Kearifan Lokal Cina: “Mianzi” dan “Lian”}

Kata politeness dalam bahasa Inggris mempunyai padanan limao dalam bahasa Mandarin. Kata limao secara historis berkaitan dengan kata li yang merujuk pada pemikiran seorang filosof Cina klasik, K’ung Fu Tsu yang hidup 551-479 SM. Filosof tersebut hidup pada era sistem perbudakan dan terjadi peperangan yang terus-menerus antarpenguasa yang feodal. Untuk mengatasi kondisi yang demikian, filosof Cina tersebut menawarkan perbaikan yang disebutnya li, yaitu sebuah model tatanan masyarakat ideal. Dua ribu tahun setelah Konghucu wafat, konsep li sebagai tatanan kehidupan tetap dipertahankan oleh para pengikutnya. Kemudian pada era dinasti Han ditemukan sebuah buku yang berjudul Li Ji yang ditulis oleh seorang laki-laki bernama Dai Sheng. Dalam baris pembukanya ditemukan suatu ajaran. "Bertuturlah yang santun, yang rendah hati, dan hormati orang lain." (Tian dan Zhao, 2006:77).

Berkaitan dengan limao, ada dua hal yang patut diperhatikan yaitu mianzi dan lian. West dan Turner (2008:161) menyebutnya dengan mien-tsu dan lien, yaitu konsep muka yang telah mengalami evolusi bertahun-tahun yang merujuk pada konsep identitas dan ego. Konsep ini dikenalkan oleh Hsien Chin Hu dalam artikelnya yang berjudul The Chinese concept of face yang dimuat pada 
American Antrophologist (1944). Dalam tulisannya Hu mengatakan bahwa konsep muka dalam masyarakat Cina modern sebenarnya berakar dari nilai-nilai budaya tradisional yang dikembangkan oleh K'ung Fu Tsu ketika memberikan wejangan tentang hakikat nilai-nilai manusia yang dikenal dengan ren. Dikemukakan lebih lanjut bahwa muka yang dibedakan atas mianzi dan lian bagi masyarakat Cina adalah harga diri yang diperoleh seseorang sebagai penghargaan dari masyarakat sekitarnya. Sebagai atribut sosial, nilai-nilai sakral muka akan dipertahankan para pemiliknya. Seseorang akan merasa malu dan kehilangan muka kalau berbuat salah apalagi berbuat nista (Aziz, 2007: 48). Dalam wikipedia, lian diartikan sebagai "The confidence of society in a person's moral character", sedangkan mianzi didefinisikan sebagai "represents social perceptions of a person's prestige." Konsep muka yang ditawarkan oleh Hu tersebut kemudian dielaborasi oleh Goffman dan digunakan untuk mengkaji interaksi sosial. Teori Goffman yang terkenal adalah teori darmaturgi yang menganalogikan kehidupan nyata di masyarakat itu ibarat panggung pertunjukkan dan dalam panggung tersebut pelakon harus saling menjaga muka (Goffman, 1959).

\section{Model Kesantunan Timur Yueguo Gu}

Di Cina, studi tentang kesantunan mulai dilakukan dengan serius pada era 80-an. Salah satu tokoh penggeraknya adalah Prof. Yueguo Gu dari Beijing Foreign Studies University (Tian dan Zhao, 2006: 76). Dalam kajian-kajiannya tentang kesantunan masyarakat Cina modern, Gu menemukan model kesantunan yang relevan dengan budaya Cina yang diformulasikan dalam maksim-maksim kesantunan yang dipandang cocok untuk lingkungan masyarakat Cina.

Pada dasarnya teori kesantunan Gu mengacu pada model kesantunan Leech (1993) tentang prinsip kesantunan. Prinsip kesantunan Leech bersifat deskriptif, bukan preskriptif. Sebaliknya, ketika mendeskripsikan konsep kesantunan (limao), Gu menekankan kenyataan bahwa pada hakikatnya secara moral prinsip kesantunan bersifat preskriptif dan bahwa kaidah atau maksim-maksim yang dikandungnya merupakan aksioma-aksioma moral yang dapat diberi sanksi sosial.

Berkaitan dengan konsep muka, Gu tidak memandang berkaitan dengan keinginan-keinginan psikologis individual, tetapi lebih memandangnya dalam kaitan dengan norma-norma kemasyarakatan. Kesantunan tidak bersifat instrumental, tetapi lebih bersifat normatif. Muka terancam bukan ketika keinginan-keinginan individu seseorang tidak terpenuhi, tetapi lebih ketika mereka gagal bertindak sesuai dengan standar-standar sosial, yaitu ketika mereka gagal memenuhi keinginan masyrakat (Eelen, 2001: 11).

Lebih lanjut dikemukakan oleh Gu (Eelen, 2001: 11-12) bagi orang Cina, prinsip kesantunan dianggap sebagai keyakinan yang disetujui bahwa perilaku seseorang perlu disesuaikan dengan harapan-harapan rasa hormat, kesederhanaan, kehangatan sikap, dan kehalusan budi bahasa. Gu mengajukan empat maksim kesantunan, yaitu (1) sikap merendahkan diri sendiri, (2) sapaan, (3) kebijaksanaan, dan (4) kedermawanan.

Maksim merendahkan diri sendiri mengingatkan penutur untuk merendahkan diri sendiri dan meninggikan orang lain. Maksim sapaan berbunyi, "Sapalah lawan bicara Anda dengan sapaan yang sesuai”. Kesesuaian di sini merujuk pada status sosial, peran pendengar, dan hubungan antara penutur dan pendengar. Maksim kebijaksanaan dan maksim kedermawanan yang diajukan oleh Gu hampir sama dengan maksimnya Leech. Maksim kebijaksanaan Leech (1993) berbunyi, "Buatlah keuntungan diri sendiri sekecil mungkin, buatlah kerugian diri sendiri sebesar mungkin”, sementara maksim kedermawanan berbunyi "Buatlah kerugian orang lain sekecil mungkin, dan buatlah keuntungan orang lain sebesar mungkin.” 


\section{Konsep Muka dan Teori Kesantunan Brown dan Levinson}

Berbeda dengan Hu yang melihat muka dari perspektif sosial, konsep muka Brown dan Levinson lebih mangacu pada kebebasan individual. Dalam pandangan Brown dan Levinson (1987), muka sebagai citra diri seorang individu terdiri atas dua keinginan yang berlawanan, yaitu muka negatif dan muka positif. Muka negatif adalah keinginan agar tindakan-tindakan seseorang tidak dihalangi oleh orang lain, sedangkan muka positif adalah keinginan agar seseorang disenangi oleh orang lain. Kesantunan berbahasa merupakan suatu cara untuk memelihara dan menyelamatkan muka dari tindak pengancaman muka (face threatening acts).

Dan Levinson (1987:65-68) membedakan kategori face threatening acts (FTA) berdasarkan dua kriteria, yaitu jenis muka yang diancam dan muka siapa yang diancam. Berdasarkan kriteria pertama, ada dua kategori FTA, yaitu FTA yang mengancam muka negatif mitra tutur (Mt) dan FTA yang mengancam muka positif penutur (Pn). FTA yang mengancam muka negatif Pn antara lain: (1) tindak yang mengakibatkan mitra tutur menyetujui atau menolak melakukan sesuatu, seperti memerintah, meminta, memberi nasihat, memberi saran, mengingatkan, mengancam, dan menantang; (2) tindak yang mengungkapkan upaya Pn melakukan sesuatu terhadap mitra tutur dan memaksa mitra tutur untuk menerima atau menolak tindakan tersebut, misalnya menawarkan dan berjanji; (3) tindak yang mengungkapkan keinginan penutur untuk melakukan sesuatu terhadap mitra tutur atau apa yang dimiliki oleh mitra tutur, misalnya memberi ucapan selamat, mengagumi, membenci, dan marah.

FTA yang mengancam muka positif Mt menurut Brown dan Levinson (1987:66-67) antara lain meliputi: (1) tindak yang memperlihatkan bahwa Pn memberi penilaian negatif terhadap Mt seperti mengungkapkan sikap tidak setuju, mengkritik, menghina, dan menuduh dan (2) tindak yang memperlihatkan sikap tidak peduli Pn terhadap muka positif Mt seperti mengungkapkan emosi, membicarakan hal yang dianggap tabu, mengungkapkan berita buruk, memotong pembicaraan, menyapa dengan sapaan yang tidak patut.

Lebih lanjut, Brown dan Levinson (1987:69) menyatakan bahwa dalam melakukan FTA seorang model person dapat menggunakan salah satu dari lima strategi yang ditawarkan, yaitu (1) melakukan tindak tutur secara langsung /apa adanya tanpa basa-basi (bald on record), (2) melakukan tindak tutur dengan menggunakan strategi kesantunan positif, (3) melakukan tindak tutur dengan menggunakan strategi kesantunan negatif, (4) melakukan tindak tutur secara tersamar/tidak langsung (off record), dan (5) bertutur dalam hati atau tidak melakukan tindak tutur.

Pilihan strategi kesantunan menurut pandangan Brown dan Levinson dapat digambarkan sebagai berikut (Gambar 1).

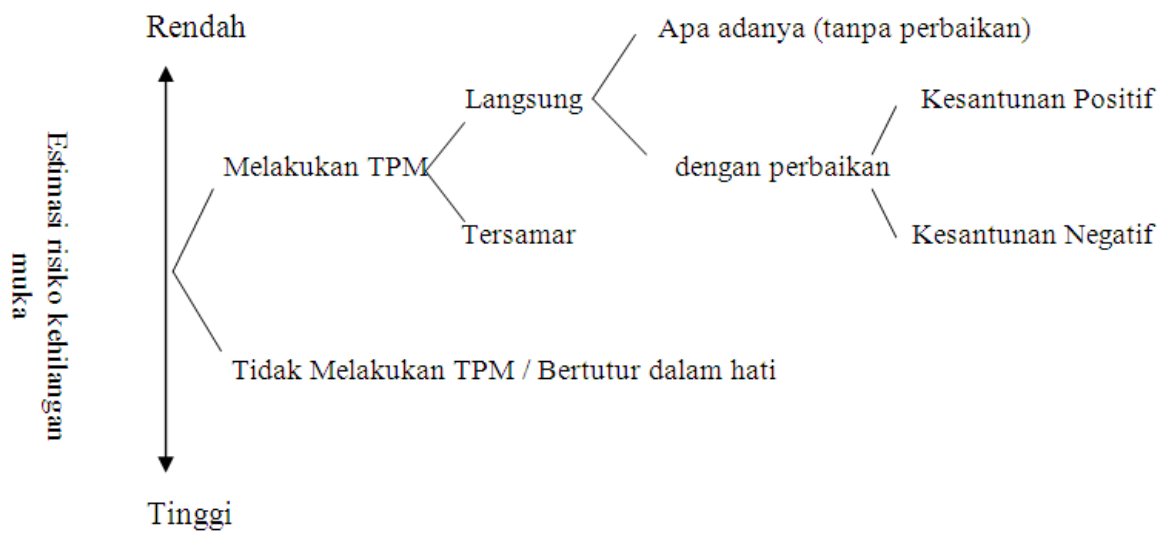

Gambar 1. Strategi kesantunan menurut pandangan Brown dan Levinson (Pramujiono, 2012). 
Strategi kesantunan positif yang ditawarkan oleh Brown dan Levinson (1987) meliputi: (1) memperhatikan kesukaan, keinginan, dan kebutuhan pendengar, (2) membesar-besarkan perhatian, persetujuan, dan simpati kepada pendengar, (3) mengintensifkan perhatian pendengar dengan pendramatisiran peristiwa atau fakta, (4) menggunakan penanda identitas kelompok (bentuk sapaan, dialek, jargon atau slang), (5) mencari persetujuan dengan topik yang umum atau mengulang sebagian /seluruh ujaran, (6) menghindari ketidaksetujuan dengan pura-pura setuju, persetujuan yang semu (psedo-agreement), menipu untuk kebaikan (white-lies, Pemagaran opini (Hedging opinions), (7) menunjukkan hal-hal yang dianggap mempunyai kesamaan melalui basa-basi (small talk) dan presuposisi, (8) menggunakan lelucon, (9)menyatakan paham akan keinginan pendengar, (10) memberikan tawaran atau janji, (11) menunjukkan keoptimisan, (12) melibatkan penutur dan pendengar dalam aktivitas, (13) berikan pertanyaan atau meminta alasan, (14) menyatakan hubungan secara timbal balik (resiprokal), dan (15) memberikan hadiah (barang, simpati, perhatian, kerja sama) kepada pendengar (Pramujiono, 2008).

Strategi kesantunan negatif yang ditawarkan Brown dan Levinson (1987) meliputi: (1) pakailah ujaran tidak langsung (yang secara konvensional memang dipakai oleh masyarakat bersangkutan), (2) pakailah pagar (hedge), (3) tunjukkan pesimisme, (4) minimalkan paksaan, (5) berikan penghormatan, (6) mintalah maaf, (7) pakailah bentuk impersonal, (8) ujarkan tindak tutur itu sebagai ketentuan yang bersifat umum.

\section{Teori Kesantunan: Perlukah Pemisahan antara Timur dan Barat?}

Banyak kajian yang membandingkan persepsi kesantunan antara Timur dan Barat. Misalnya kajian Hiraga dan Turner(1996) tentang perbedaan persepsi tentang muka masyarakat Inggris dan Jepang dengan latar akademik; Tian dan Zhao (2006) yang melakukan studi kontrastif antara konsep kesantunan barat dan Cina. Kajian lintas budaya semacam itu banyak berkembang setelah Brown dan Levinson memublikasikan pikirannya pada tahun 1978 (Leech, 2007). Kajian yang dilakukan oleh pakar dari timur seperti Ide (1993), Mastumoto (1989), Gu (1990), dan Mao (1994) menurut Leech cenderung mengklaim bahwa konsep muka pada konteks kesantunan Barat cenderung bersifat individualis dan bermotif egalitarian, sedangkan bagi orang Timur muka berkaitan dengan tataran hierarki sosial dan norma-norma yang melingkupinya.

Guna membuktikan kebenaran pandangan tersebut, Leech (2007) melakukan penelitian terhadap empat bahasa, yaitu Cina, Jepang, Korea, dan Inggris dengan menggunakan grand strategy of politeness (GSP) yang dikembangkan pada pola perilaku linguistik secara umum pada performansi tindak tutur yang santun seperti permintaan, penawaran, pujian, permintaan maaf, ucapan terima kasih dan respon terhadap tindak tutur tersebut. Konteks tuturan dibedakan pada hubungan antarinteraktan yang menempatkan mitra tutur pada dua posisi: pertama, mitra tutur dipandang memiliki "nilai” yang lebih tinggi dan kedua, mitra tutur dipandang mempunyai "nilai” yang lebih rendah.

Berdasarkan penelitiannya tersebut, Leech memberikan simpulan yang masih tentatif bahwa meskipun teori Brown dan Levinson dikritik tidak bersifat universal dan memiliki bias relativitas pada berbagai konteks masyarakat yang berbeda, Leech berkeyakinan masih tetap ada hal-hal yang sama sebagai dasar perilaku dan kaidah pragmatik secara umum berkaitan dengan kesantunan. Ketika limao dibedakan dengan politeness, pembedaan tersebut tidak dilakukan sebagai ketidakberhubungan secara total. Ada fenomena-fenomena yang dapat digunakan untuk membuktikan keuniversalan kesantunan meskipun masih agak prematur. Perbedaan interpretasi dari berbagai masyarakat tutur tersebut dapat dijadikan dasar dalam kajian pragmatik lintas budaya.

Leech (2007:201) lebih lanjut menegaskan pembedaan timur-barat tidak perlu dilakukan karena skala kesantunan dapat digunakan untuk mengekspresikan perbedaan-perbedaan nilai, baik secara kualitatif maupun kuantitatif. Cina dan Jepang memiliki perbedaan budaya, tetapi mereka 
dipengaruhi oleh tradisi yang sama yaitu ajaran konfusius yang lebih mengutamakan harmoni masyarakat di atas kebebasan individu. Perilaku seseorang akan bermakna dalam komunitasnya ketika ada partisipasi dari yang lain. Di sinilah ego disingkirkan dan kebersama-an/kesatuan dalam sebuah harmoni dibangun. Di sisi lain, perilaku individualis, egalitarian sebagai label Barat diekspresikan dalam kesantunan dengan mempertimbangkan berbagai faktor misalnya pembobotan yang lebih tinggi terhadap perilaku bijak (tindakan menghargai mitra tutur) dan pembobotan yang lebih rendah terhadap kerendahan hati (pemaksaan kehendak lebih dianggap baik). Namun yang perlu diketahui, bahwa orientasi egaliter itu tidak memberikan asumsi bahwa masyarakat Barat lebih individualis dan egalitarian dibanding masyarakat yang lain. Walaupun terkadang memang mereka lebih egaliter.

Dari pandangan Leech di atas dapat ditarik simpulan bahwa secara mendasar dari aspek pragmatik tidak perlu pembedaan kesantunan Timur dan Barat. Karena skala kesantunan dapat digunakan untuk mengekspresikan perbedaan-perbedaan nilai, tetapi persepsi terhadap ekspresi kesantunan dapat saja berbeda sesuai dengan konteks budaya masyarakatnya. Di sinilah parameter $\mathrm{R}$ (Ranking of impositions in the particular culture) yang diajukan oleh Brown dan Levinson (1987: 76) memiliki peran yang penting.

\section{SIMPULAN}

Sebagai orang Timur kita boleh bangga, konsep muka dalam teori kesantunan Brown dan Levinson (1987) yang dianggap sebagai kesantunan yang paling berpengaruh dan mendunia, ternyata berakar dari kearifan lokal Timur (Cina Klasik) yaitu mianzi dan lian. Mianzi merepresentasikan persepsi sosial tentang harga diri seseorang yang dibangun melalui lian sebagai moralitas seseorang. Politeness dan limao memiliki dasar pragmatik yang sama, tetapi dapat dipersepsi berbeda karena berbagai konteks budaya yang melatari suatu masyarakat tutur. Perbedaan tersebut dalam konteks kajian pragmatik lintas budaya tidak seharusnya menjadi sumber perselisihan dan permusuhan, tetapi justru perlu disikapi sebagai keragaman yang antarinteraktan perlu saling memahami sehingga aktivitas komunikasi interpersonal dapat berlangsung secara harmonis terhindar dari berbagai friksi dan konflik.

\section{DAFTAR PUSTAKA}

Brown, P. dan Levinson, S.C. (1987). Politeness Some Universals in Language Usage. New York: Cambridge University Press.

Disertasi tidak diterbitkan. Universitas Negeri Surabaya, Surabaya.

Eelen, G. (2001). Kritik Teori Kesantunan (Jumadi dan Slamet Rianto, terj.). Surabaya: Airlangga University Press.

Goffman, E. (1959). The Presentation of Self in Everyday Life. New York: A Doubleday Anchor Original.

Hiraga, M.K. and Turner, J.M. (1996). Differing perceptions of face in British and Japanese academic settings. Language Sciences, 18, (3 - 4), ISSN 0388-001.

Leech, G. (1993). Prinsip-Prinsip Pragmatik. (M.D.D. Oka, terj.) Jakarta: UI Press. 
Leech, G. (2007). Politeness: Is there an East-West divide? Journal of Politeness Research Language, Behavior, Culture, 3, (2), 167 - 206, ISSN 1613-4877.

Pramujiono, A. (2008). Kesantunan positif komunikasi dokter-pasien dalam program konsultasi seks. Linguistik Indonesia: Jurnal Ilmiah Masyrakat Linguistik Indonesia, 26, (2), 151 - 167.

Pramujiono, A. (2012). Kesantunan Berbahasa dalam Wacana Dialog di Televisi.

Tian, X. and Zhao, H. (2006). Specificity of politeness contrastive study of western and chinese concepts of politeness. Sino-US English Teaching, 3 (2), ISSN 1539-8072.

West, R. and Turner, L.H. (2008). Pengantar Teori Komunikasi Analisis dan Aplikasi. (Maria Natalia Damayanti Maer, terj.). Jakarta: Salemba Humanika. 